
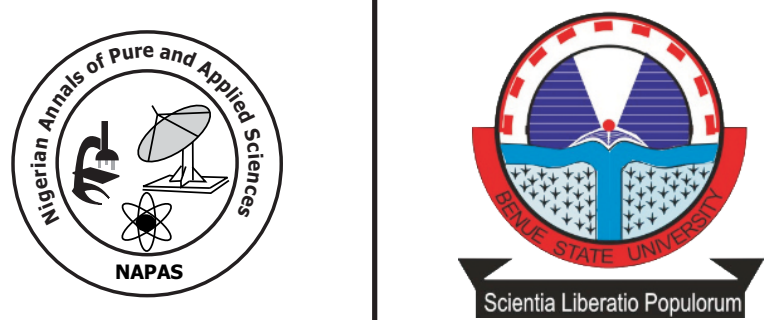

\title{
Fractal Characterization of Earthquake occurrences in Nigeria
}

\author{
Abdulsalam, N.N. ${ }^{1}$ and Ologe, $\mathbf{0 .}^{2}$ \\ ${ }^{1}$ Department of Physics, \\ University of Abuja, Nigeria \\ ${ }^{2}$ Department of Applied Geophysics, \\ Federal University Birnin Kebbi, Nigeria \\ *Corresponding authors: abdulsalam.naeem@uniabuja.edu.ng
}

\begin{abstract}
Fractal characterization of Earthquake occurrences in Nigeria was carried out in order to know the bvalue of tremor occurrences in the country. This will help in hazard analysis and research in the geological and geophysical structures of Nigeria. The method used in determining the b-value is the box counting method, but for simplicity, we used circle. The areas that are tremor prone were posted on a digitized Nigeria map using Google earth and Surfer 7.0 software. The computation with the box counting method was performed with selected radius of the circle from $50 \mathrm{~km}-350 \mathrm{~km}$ and the average number of points that falls within each circle were recorded. The graph of $\log r$ (the logarithms of radius of circle or scale) against $\log <\mathrm{N}>$ (logarithms of average number of points) was plotted using grapher and excels Microsoft word and the slope of the graph was determined. The determined slope gave the fractal dimension and the $\mathrm{b}$-value was thus calculated. In this work, a b-value of 0.6 was obtained indicating that Nigeria falls within seismically less active zone.
\end{abstract}

Key words: Earthquake, fractal characterization, b-value, geological history, seismic activity 


\section{Introduction}

History of earthquake occurrences in Nigeria as reported by Akpan and Yakubu (2010) indicates that although Nigeria is not located within the major seismic zones of the world; several minor earthquakes have been experienced in some parts of the country over the years. The first widely reported occurrence of an earth tremor in Nigeria was in 1933. Other events were reported in 1939, 1964, 1984, 1990, 1994, 1997, 2000, 2006 and 2016. The intensities of these events ranged from 3 to 6 based on the modified mercalli intensity scale. Of these events, only the 1984 , 1990, 1994 and 2000 events were instrumentally recorded. They had body wave magnitudes ranging from 4.3-4.5, local magnitudes between 3.7 and 4.2 , and surface wave magnitudes of 3.7 to 3.9. [Akpan and Yakubu, 2010]. When these events occurred, there were no functional seismological observatories in Nigeria. However, that has now changed with the establishment of a seismographic network managed by the centre for Geodesy and Geodynamics (CGG) Toro, Bauchi State.
Nigerian scientists at the National Space Research and Development Agency (NARSDA) warned that Nigeria should be prepared for earthquake experience. The NARSDA researchers said the tremor is a sign that Nigeria is not immune from earthquake occurrence. Adepetumi (2011) reported that the country is not in the earthquake safe region. Since Nigeria lies on the flank of the Atlantic Ocean, the present of fracture zones which prominently traverse the western half of Nigeria had been pointed out as a prime cause of seismic activities within the western part of Nigeria. This mega structure named Ifewara-Zungeru fault (Figure 1) is the longest linear feature within the Precambrian basement complex of Nigeria and stretches from east of Ijebu-Ode in the South, through Ifewara, Iwaraja and Okemesi, to the basin of River Niger, South of Lafiagi to Zungeru and beyond to Kalangai in Northwestern Nigeria. It should be noted that the reported occurrence of an earthquake in Lupma which lie along the northward extension of this fault also support the existence of this fault zone. (Odeyemi, 2006).

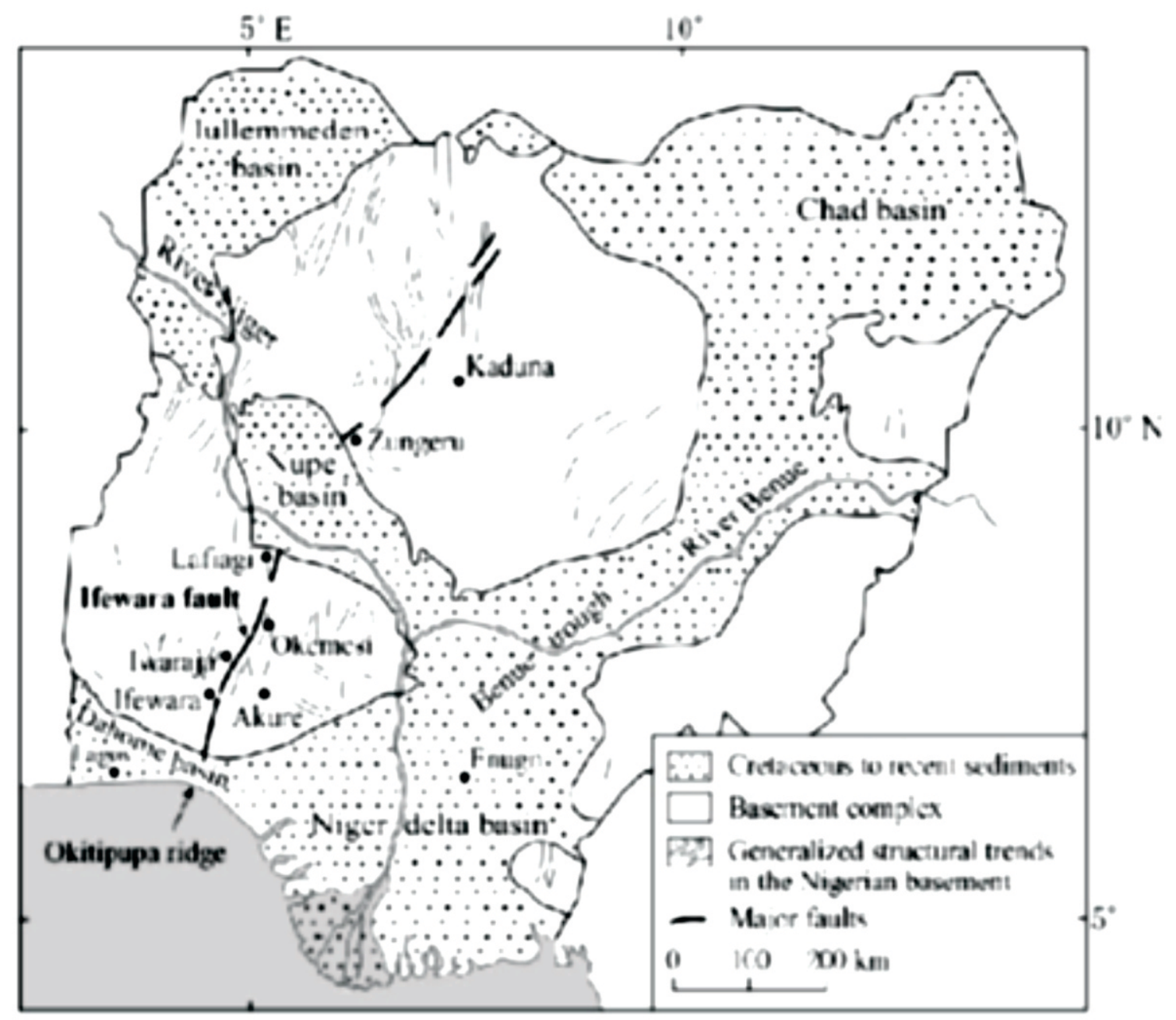

Figure1: Geological map of Nigeria showing the Ifewara-Zungeru Fault (adapted from Odeyemi, 2006). 
The occurrences of earth tremor in Yola and Gembu areas in the north-eastern part of the country might be related to seismic activities in Mt. Cameroun due to the proximity of these areas to Mt. Cameroun. (Ugodulunwa et al. 1986)

The seismic events of $28^{\text {th }}$ July, 1984, $27^{\text {th }}$ June, 1990 and $7^{\text {th }}$ March,2000 within the South Western part of Nigeria aroused the consciousness of Nigeria Geoscientist to the fact the country might not be tectonically stable as thought. Furthermore, remote sensing, geological and geophysical evidences have revealed the presence of deep seated NNE-SSW lineament (the IfewaraZungeru fault) which transcend the western half of the country. These Precambrian fractures are thought to be linked with some transform fracture zones in the Atlantic Ocean. Some scholars have suggested that the possible triggering mechanism of the Nigeria earth tremors might be associated with these fracture zones. [Elueze, 2003]. However, as the country prepare to go into nuclear energy generation, it is pertinent that Nigeria know the right places to site the nuclear power stations in term of seismology to prevent what happened in Japan, in February 2011. The need for fractal characterization of earthquake occurrences in Nigeria arises because certain industries like Nuclear power stations need to be sited in seismic free zones and if there is no alternative site, then earthquake resistance building may be of economic value.

\section{Description of Past and Recent Activities of Earthquakes in Nigeria.}

The history of earthquake occurrences in Nigeria dated back to the 1930 's when tremor was reported in some parts of warri in 1933 and Ibadan on $22^{\text {nd }}$ June 1939. The 1939 event was also felt in part of Ile Ife and Lagos and was probably related to the Accra earthquake that occurred on the same day. (Ajakaiye et al,1987). Another reported event occurred on $21^{\text {st }}$ December 1963 at about 18:30 GMT near Ijebu-Ode with an epicentral intensity of about five. The event that generated much attention and which also received wide publicity occurred on Saturday, July 28, 1984 and was felt in Ibadan, Ijebu-Ode, Shagamu and Abeokuta in southwestern Nigeria. This was also due to the fact that these areas lie within the Nigeria basement complex which was hitherto stable tectonically. (Ajakaiye et al,1987). The tremor was strongly felt by a good number of people in these areas, building and trees were shaken, items on shelves fell down and the time of occurrences was given as 12:10 GMT. The two vibrations that accompanied the event in Ibadan area, the first which was probably a foreshock, occurred as a mild vibration that the walls of building with the clattering of louvers and lasted about ten seconds. The second which was the main shock happened about five minute later and was more violent as buildings were shaken with their floors undulating contemporaneously. (Ajakaiye et al 1987).

Another event that attracted much attention occurred on Wednesday, June 27, 1990, in Ibadan. This was recorded by the Geological survey of Nigeria seismological station in Ilorin and had a local magnitude of 3.7. Although, the epicentre was not given, it could be inferred that it was close to Ijebu-Ode, [Osagie, 2008]. Residents of Oluyole estate extensions, Apata, Odoowa and Felele areas of Ibadan experienced the highest shaking, which lasted less than 10 seconds. There were violent vibrations of building foundations, breaking of louvers blades of windows e.t.c. [Osagie, 2008].

On Sunday, May $7^{\text {th }} 2000$, another earth tremor was reported in Akure. The shock took place at about 11:00 GMT, and lasted about 10 seconds. It was reported that the ground was shaken to the extent that flower vases and wall mounted photographs fell off. However, no damage was recorded in buildings. Furthermore, people who were indoors mostly felt the shock. The epicentral intensity of this event was five, [Osagie, 2008].

On $25^{\text {th }}$ March 2006 at about 11:20 GMT, a suspected earth tremor was reported in a rural settlement of Lupma near Minna, northern Nigeria. Some people who were working in their farm had to run for safety. Eye witness accounts, have it that sudden vibration was felt around the area and sound like that of moving train was heard. There were cracks in buildings, rocky outcrops within the immediate vicinity of the vibration seriously shattered. There was an aftershock after about ten seconds. A maximum epicentral intensity of four was assigned to the event. [Akpan and Yakubu, 2010].

\section{Argument for Nigeria's Seismological Safety.}

Nigeria was thought to be aseismic, and this development made Nigeria geoscientist develop a lackadaisical attitude towards research into the occurrence of earthquakes in the country, hence very little has been done prior to 1984 . The fact 
that Nigeria is not tectonically stable as earlier thought has generated much debate as evident in Kwoi (2016), Mpape and Maitama (2018) tremors. The Ifewara-Zungeru fault, Odeyemi, 2006 reported that this Precambrian fracture, as scholars have pointed out posed a big seismological threat to the country especially the south-west zone of the country. This will require further investigation into Nigeria seismological structure. With the establishment of the centre for Geodesy and Geodynamics, Toro and the upgrading of the seismic equipment in its four stations located in Kaduna, Nsukka, Oyo and IleIfe and newly acquired seismometers located in Nigeria Geological Survey Agency, University of Abuja, Nassarawa state University, Keffi and Veritas University Bwari shows that the country is ready for the business of research into its seismology.

\section{Theoretical Background of Fractal Dimension.}

The term fractal dimension and fractal were coined by Mandelbrot in 1975, about a decade after he published his paper on self-similarity in the coastline of Britain. Various historical authorities credit him with also synthesizing centuries of complicated theoretical mathematics and engineering work and applying them in a new way to study complex geometries that defied description in usual linear terms. These works were accompanied by perhaps the most pivotal point in the development of the concept of a fractal dimension through the work of Hausdorff in the early 1900s who defined a "fractional" dimension that has come to be named after him and is frequently used in defining modern fractals. [Turcotte 1992].

Fractal dimension is a measure of how "complicated" a self-similar figure is. In a simple sense, it measures "how many points" lie in a given set. A plane is "larger" than a line, while Ssits somewhere in between these two sets.

From Turcotte [1992], the fractal dimension is given by the relation;

$\mathrm{D}=\log \mathrm{N} \div \log \mathrm{r} . \ldots \ldots \ldots \ldots \ldots \ldots \ldots \ldots \ldots$

Where $\mathrm{N}=$ Number of objects, and $\mathrm{r}=$ scale.

\section{Methodology}

The scaling of the Map

The scale for the map was obtained by choosing two points on the map, and knowing that one degree represent about $111.12 \mathrm{~km}$, a scale of $1 \mathrm{~cm}: 3,895,000$ was obtained.

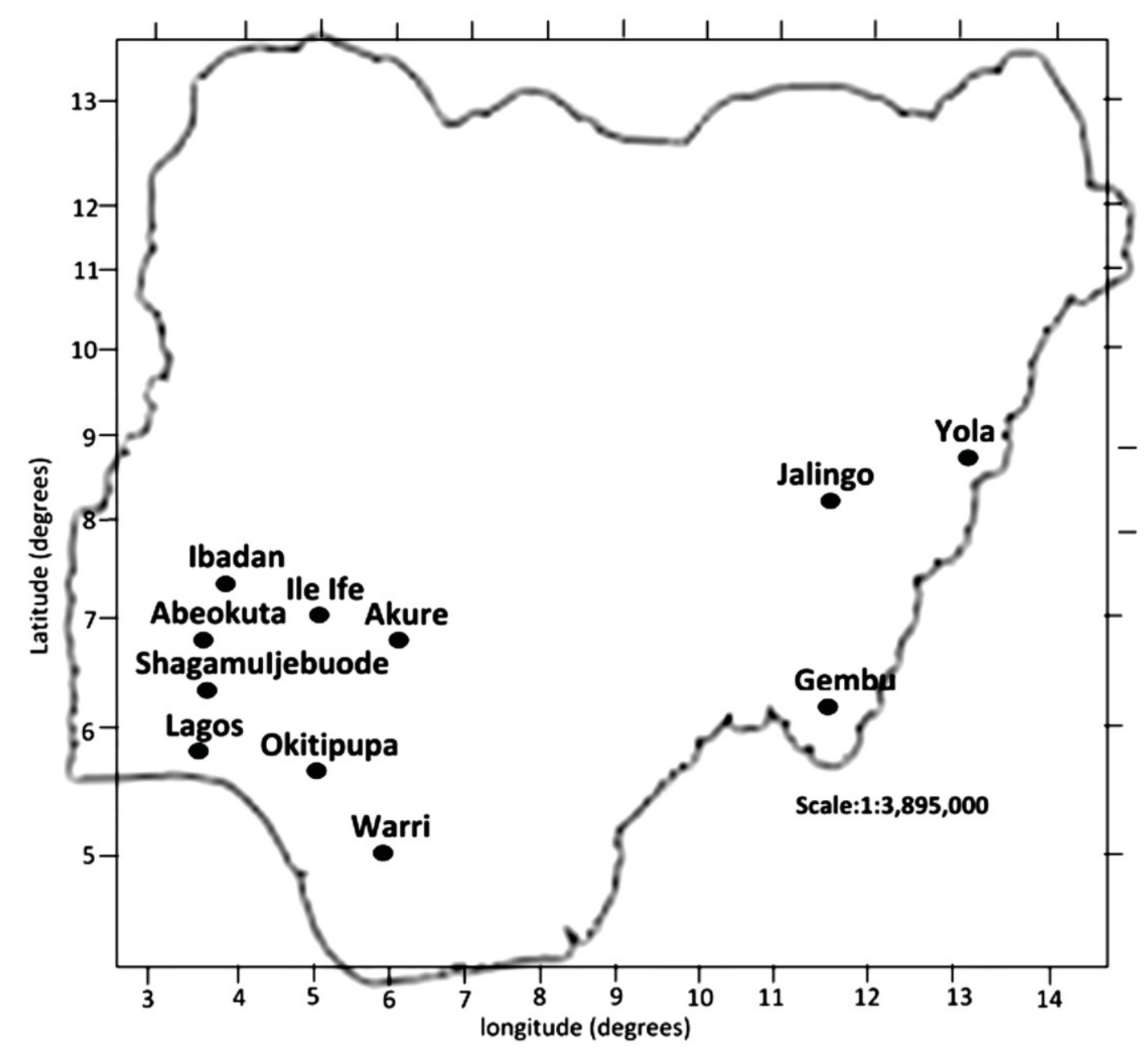




\section{The box counting method of determining fractal Dimension (D).}

The method used in this work in determining fractal dimension is the box counting method, in this method a box is inscribed on the point of tremor on the Nigeria map, in our case, we used circle of known radius for simplicity. When a circle of specific radius ( $r$ ) is placed on a point of earth tremor on the map, other point (s) that fall in that radius is noted, the same radius is placed on another point until all the points are covered. Another radius is chosen and the same procedure is repeated with all the points and the average of the points $<\mathrm{N}>$ that corresponds with each radii chosen is calculated.

The logarithm of $r$ is plotted against logarithm of $<\mathrm{N}>$ (the average of points within each circle of specified radius). A straight line graph is plotted and the slope gives the fractal dimension (D), from which the b-value is calculated. The fractal dimension (D) is related to the "b-value" as thus,

$2 b=D$......

Where $\mathrm{D}=$ Fractal dimension and $\mathrm{b}=$ " $\mathrm{b}$-value".

\section{The "b-value" and its significance.}

In seismology, the Gutenberg-Richter Law (GR law) expresses the relationship between the magnitudes and total number of earthquakes in any given region and time period of the least magnitude.

$\log _{10} \mathrm{~N}=\mathrm{a}-\mathrm{bM}$

OR

$\mathrm{N}=10^{\mathrm{a}-\mathrm{bM}}$

Where:

- $\quad \mathrm{N}$ is the number of events having a magnitude $\geq \mathrm{M}$

- $\quad \mathrm{a}$ and b are constants [Adapted from Richter \& Gutenberg 1954]

The relationship was first proposed by Charles Francis Richter and Benogutenberg. The relationship is surprisingly robust and does not vary significantly from region to region or over time.

The constant $\mathrm{b}$ is typically equal to 1.0 in seismically active regions (Ota, 2005). This means that for every magnitude 4.0 event, there will be 10 magnitude 3.0 quakes and 100 magnitude 2.0 quakes. There are some variations with $b$-value in the range 0.5 to 1.5 depending on the tectonic environment of the region. A notable exception is, during earthquake swarms when the b-value can become as high as 2.5 , indicating an even larger proportion of small quakes to large ones (Hirata,1989):. But in our case, we are using equation 1 . The determination for the country's " $b$ value" which will help geoscientist research on the major preventive and rescuing operation suitable for such emergency as earth tremor occurrence. It is my believed that this work will arouse the curiosity of geoscientist in Nigeria into research in the country's fault systems, plate tectonics and volcanic activities in the country

The latitude and longitude of towns that have experienced earth tremor were obtained using Google earth and posted on a digitize map of Nigeria. The scale of the map was calculated to be 1: $38,895,000$ using the fact that one degree approximate $111 \mathrm{~km}$.

The radius of the circle was chosen so that it is not too small or too large. So we started by letting $\mathrm{r}_{1}=50 \mathrm{~km}$. The conversion is as follows; For $\mathrm{r}_{1}=\mathrm{km}, 1 \mathrm{~cm}=38.95 \mathrm{~km}$ from the scale of the map.

- $\quad$ For $_{1}=50 \mathrm{~km}$

The average number of points that falls on a circle of this radius is $<\mathrm{N}_{1}>=1.41$.

- $\quad$ For $_{2}=100 \mathrm{~km}$,

The average number of points that falls on a circle of this radius is $\left\langle\mathrm{N}_{2}\right\rangle=3.41$.

- $\quad$ For $_{3}=150 \mathrm{~km}$,

The average number of points that fall on a circle of this radius is $<\mathrm{N}_{3}>=5.16$.

- $\quad$ For $_{4}=200 \mathrm{~km}$,

The average number of points that fall on a circle of this radius is $<\mathrm{N}_{4}>=5.91$.

- $\quad$ For $r_{5}=250 \mathrm{~km}$,

The average number of points that fall on a circle of this radius is $<\mathrm{N}_{5}>=6.66$.

- $\quad$ For $_{6}=300 \mathrm{~km}$

The average number of points that fall on a circle of this radius is $<\mathrm{N}_{6}>=7.25$.

- $\quad$ For $_{7}=350 \mathrm{~km}$

The average number of points that fall on a circle of this radius is $<\mathrm{N}_{7}>=7.50$.

\section{Computational Software used.}

- Graphers; This is a software programme used in computing various relations graphically, this includes; bar chart, pie chart, histogram, function, step plot, vector plot and 3D xyz bar chart.

- Google Earth; This software package help locate places on earth with its geographical and geological details. 
- Surfer 7.0: this software programme is used in drawing and analyzing various types of maps; base map, grid map and so on. It is also used in

posting points on maps.

\section{Results and Discussion.}

Table 1: Table showing the values of $r$ and the average number of points $<N>$.

\begin{tabular}{lccccc}
\hline $\mathrm{S} / \mathrm{n}$ & $\mathrm{r}(\mathrm{cm})$ & $\mathrm{r}(\mathrm{km})$ & $<\mathrm{N}>$ & Logr $(\mathrm{km})$ & $\log <\mathrm{N}>$ \\
\hline 1 & 1.28 & 50 & 1.41 & 1.69 & 0.149 \\
2 & 2.56 & 100 & 3.41 & 2.00 & 0.532 \\
3 & 3.85 & 150 & 5.16 & 2.17 & 0.712 \\
4 & 5.13 & 200 & 5.91 & 2.30 & 0.771 \\
5 & 6.40 & 250 & 6.66 & 2.39 & 0.823 \\
6 & 7.70 & 300 & 7.25 & 2.47 & 0.860 \\
7 & 8.98 & 350 & 7.50 & 2.54 & 0.875 \\
\hline
\end{tabular}

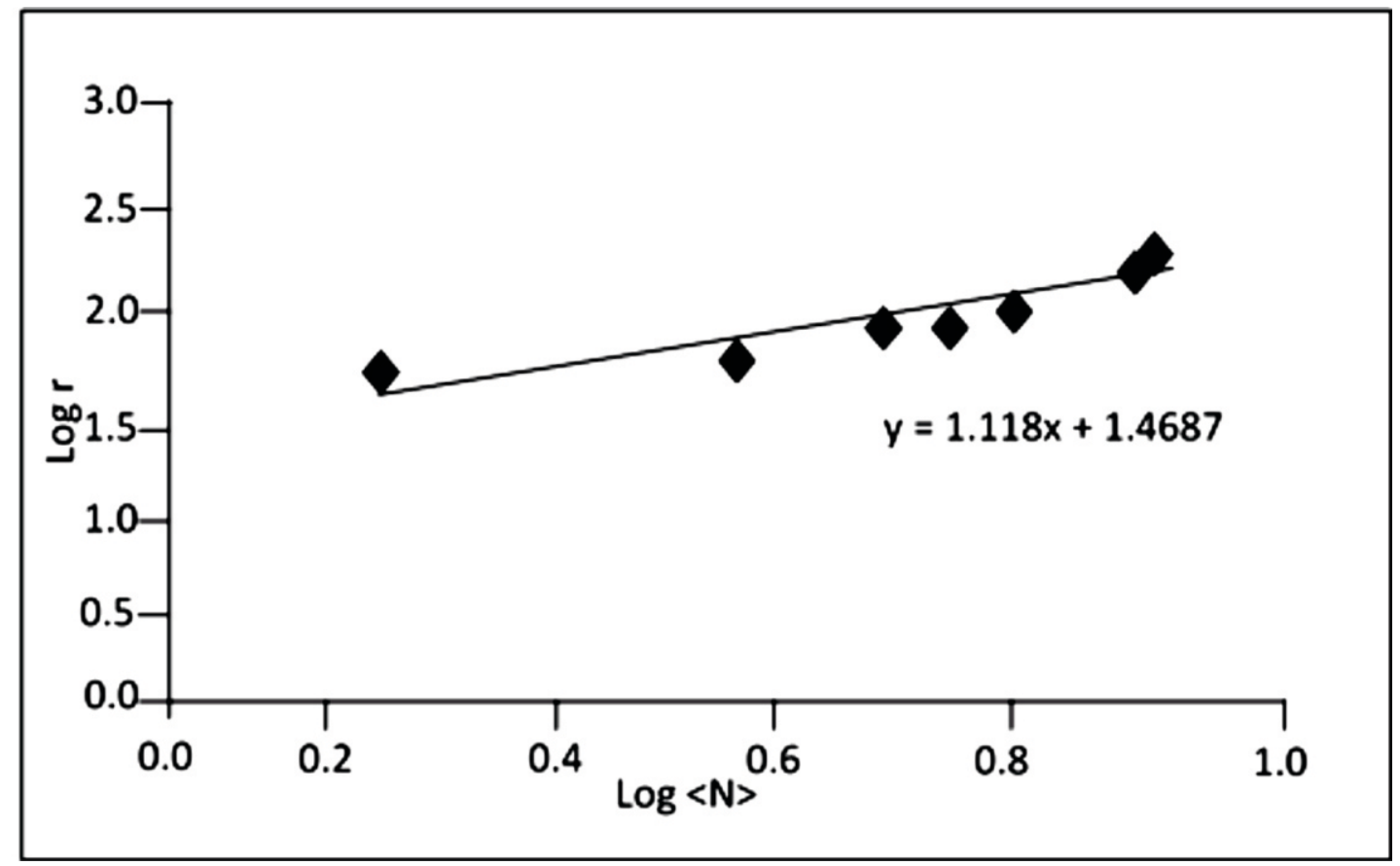

Figure 2: Graph of $\log (\mathrm{r})$ against $\log <\mathrm{N}>$

From the graph of $\log \mathrm{r}$ on the Y-axis against $\log \langle\mathrm{N}\rangle$ on the $\mathrm{X}$-axis, there was a straight line, whose slope gives 1.118.

From the b-value fractal dimension relationship, $\mathrm{D}=2 \mathrm{~b}$................ 4

Therefore b-value can be calculated from equation (4) as thus;

$\mathrm{D}=2 \mathrm{~b}$, but $\mathrm{D}=$ slope $=1.118$.

Therefore our b-value is approximately 0.6 . Note that $b$-value is dimensionless.

In order to get the b-value of Nigeria, a method known as box counting was employed to determine the fractal dimension (D) in our calculation where a circle of known radius was placed on a point of earth tremor on the map. Other points that fell in that radius were noted. The same radius was placed on other points until all the points were covered. This procedure was repeated for seven different radii on the point of earth tremor on the map. The average number of points within each circle of specified radius given as $(\mathrm{N})$ was also noted.

After representing $1 \mathrm{~cm}$ of the radius to equal $38.95 \mathrm{~km}$, then for the given radii in $\mathrm{km}$, we can now convert it to $\mathrm{cm}$ as seen below

For the first radiusi.e.( $\mathrm{rl}$ ) which is $50 \mathrm{~km}$,we can convert it to $\mathrm{cm}$ by simply dividing by 38.95 which gives $1.28 \mathrm{~cm}$ and $\mathrm{N}$ was gotten to be 1.41 from the map.

The second radius $\left(\mathrm{r}_{2}\right)$ was $100 \mathrm{~km}$ and it was converted $2.56 \mathrm{~cm}$ with $\mathrm{N}$ gotten to be 3.41 from the map.

The third radius $\left(\mathrm{r}_{3}\right)$ was $150 \mathrm{~km}$ and it was converted to $3.85 \mathrm{~cm}$ with $\mathrm{N}$ gotten to be 5.16 from the map.

The fourth radius $\left(\mathrm{r}_{4}\right)$ was $200 \mathrm{~km}$ and it was converted to $5.13 \mathrm{~cm}$ with $\mathrm{N}$ gotten to be 5.91 from the map.

The fifth radius (r5) was $250 \mathrm{~km}$ and it was converted to $6.40 \mathrm{~cm}$ with $\mathrm{N}$ gotten to be 6.66 from the map.

The sixth radius $\left(\mathrm{r}_{6}\right)$ was $300 \mathrm{~km}$ and it was 
converted to $7.70 \mathrm{~cm}$ with $\mathrm{N}$ gotten to be 7.25 from the map.

The seventh radius $\left(\mathrm{r}_{7}\right)$ was $350 \mathrm{~km}$ and it was converted to $8.98 \mathrm{~cm}$ with $\mathrm{N}$ gotten to be 7.50 from the map.

Then the logs of $\mathrm{r}(\mathrm{km})$ and $\mathrm{N}$ values were recorded to complete the table as seen in table 4.1 above.

The graph of $\log \mathrm{r}(\mathrm{km})$ on the vertical axis was plotted against the $\log \mathrm{N}$ on the horizontal axis which gave a straight line graph and the slope was gotten to be 1.118 which gave us the value of fractal dimension (D).

Thus, we can calculate the value of the bvalue from equation 4 which is given as

$\mathrm{D}=2 \mathrm{~b}$, where $\mathrm{D}=1.118$

$\mathrm{b}=0.6$.

\section{Conclusion}

Earthquake is the result of a sudden release of energy in the earth's crust that creates seismic wave. The seismicity or seismic activity of an area refers to the frequency, type and size of the earthquakes experienced over a period of time. Fractal characterization of earthquake occurrences in Nigeria was carried out in order to know the "b-value" of tremor occurrences in the country. This will help in hazard analysis and research in the geological and geophysical structures of Nigeria. The method used in determining the b-value is the box counting method, but for simplicity, we used circle. The areas that are tremor prone were posted on a digitized Nigeria map using Google earth and surfer 7.0 software. The computation with the box counting method was performed with selected radius of the circle from $50 \mathrm{~km}-350 \mathrm{~km}$ and the average number of points that falls within each circle were recorded. The graph of $\log r$ (the logarithm of radius of circle or scale) against log $<\mathrm{N}>$ (logarithm of average number of points) was plotted using grapher and excels Microsoft word and the slope of the graph was calculated. The calculated slope gave the fractal dimension and the $b$-value was thus calculated. In this work, a bvalue of 0.6 was obtained indicating that Nigeria falls on seismically less active zone. From the calculation of $b$-value from our computation, $b$ 0.6 , indicating that Nigeria is in seismically less active region, indicating small proportion of quakes. With this result, Nigeria seismic safety is high and also, the importance of b-value is critical for hazard analysis and in the physical understanding of the geological and geophysical structure of the country.

This work recommends that Nigeria must understand the hazard level of this country as the country prepare to go into nuclear energy generation, it is pertinent that we (Nigeria) know the right places to site the nuclear power stations in term of seismology

It is also recommended for Geoscientist to help research on the major preventives and rescuing operation suitable for such emergency as earth tremor occurrences, it will also help to arouse the curiosity of geoscientist in Nigeria into research in the country fault system, plate tectonic and volcanic activities in the country.

\section{References.}

Ajakaiye, D.E; Daniyan, M.A; Ojo S.B. and Onuoha K.M. (1987). The july 28,1984 southwestern Nigeria earthquake and its implications for the understanding of the tectonic structure of Nigeria. In: Wassef A.M, BoudA, Vyskocil P. (eds), Recent Crustal Movements in Africa. Journal Geody 7; 205-214.

Akpan, O.U. and Yakubu T.A., (2010). A review of Earthquake Occurrence and observation in Nigeria. Centre for Geodesy and Geodynamic. Toro, Nigeria.

Elueze A.A., (2003). Evaluation of the March $7^{\text {th }}$, 2000 earth tremor in Ibadan area, southwest Nigeria. Jour min Geol 39(2):79-83.

Gutenberg .B. and Richter. C.F., (1954). Seismicity of the earth and associated phenomenon, $2^{\text {nd }}$ Edition, Princeton university press, Princeton.

Hirata T., (1989). A correlation between the bvalue and the fractal dimension of earthquakes, J. Geophys. Res.94,7507-14.

Odeyemi I.B., (2006). The Ifewara fault in southwestern Nigeria: its relationship with fracture zones along the Nigeria coast. Lecture delivered at the centre for Geodesy and Geodynamics, Toro, Bauchi state.

Osagie, E.O. (2008). "Seismic Activity in Nigeria". Pacific Journal of Science and Technology. 9(2):546-551.

Ota Kulhanek (2005). Seminar paper on b-value Department Of Earth Science, Seismology Uppsala University, Uppsala, Sweden. (Unpublished).

Turcotte D.L. (1992). Fractals and chaos in geology and geophysics. Cambridge University press.

Ugodulunwa F.X.O, Ajakaiye D.E, Guiraud M. And Hossan M.T., (1986). The pindiga and obi fractures possible earthquake sites in Nigeria, In proceedings of the $3^{\text {rd }}$ international conference on current research in geophysics and geophysical research in Africa, Jos, Nigeria. 